SHORT REPORT

\title{
Evaluation of propofol and remifentanil for intravenous sedation for reducing shoulder dislocations in the emergency department
}

\author{
M J G Dunn, R Mitchell, C De Souza, G Drummond
}

Emerg Med J 2006;23:57-58. doi: 10.1136/emj.2004.021410

Objectives: To assess the combination of propofol and remifentanil for sedation to reduce shoulder dislocations in an ED.

Methods: Eleven patients with anterior glenohumeral dislocation were given propofol $0.5 \mathrm{mg} / \mathrm{kg}$ and remifentanil $0.5 \mu \mathrm{g} / \mathrm{kg}$ iv over 90 seconds and then further doses of $0.25 \mathrm{mg} / \mathrm{kg}$ and $0.25 \mu \mathrm{g} / \mathrm{kg}$, respectively, if needed. Another practitioner attempted reduction using the Milch technique.

Results: Reduction was achieved in all patients within four minutes of giving sedation (range 0.3-4; mean 1.6). Seven required one attempt at shoulder reduction, three required two attempts, and one required three attempts. Mean time to recovery of alert status was three minutes (range 1-6). The mean pain score during the reduction was 1.7 out of 10 (range 0-5). Nine patients had full recall, one had partial recall, and one had no recall at all. Eight patients were "very satisfied" with the sedation and three were "satisfied". There were no respiratory or haemodynamic complications that required treatment.

Conclusions: Propofol and remifentanil provide excellent sedation and analgesia for the reduction of anterior glenohumeral dislocation, enabling rapid recovery.

A cute glenohumeral dislocation is a common presentation to emergency departments (EDs). Many methods of reduction have been described but all require a "relaxed" patient and good analgesia. This is commonly achieved by combining an intravenous opioid with a benzodiazepine.

Although studies have compared intra-articular lignocaine with intravenous sedation, using intravenous agents such as meperidine, morphine, fentanyl, midazolam, and diazepam, ${ }^{1-4}$ few studies have evaluated alternative intravenous agents for sedation. Etomidate combined with fentanyl has been used successfully for this purpose with faster recovery times. ${ }^{5}$ In this paper we describe the use of propofol and remifentanil to facilitate shoulder reduction.

We set out to assess the efficacy of propofol and remifentanil for sedation and analgesia for the closed reduction of acute anterior glenohumeral dislocation. Our local ethics committee requested that we conduct this pilot study, using careful supervision, before undertaking a comparison with our current method.

\section{METHODS}

We recruited eleven patients with acute anterior glenohumeral dislocation. We chose patients aged 16-65 years, American Society of Anesthesiologists (ASA) grade I or II, and included patients with an avulsion fracture of the greater tuberosity or of the glenoid labrum. We excluded those with more major fracture/dislocations and patients with posterior dislocations or major injuries.

Patients were pre-oxygenated with a Mapleson C circuit and a well fitting facemask. Intravenous sedation was administered by an anaesthetist in seven cases and an emergency physician in the other four. A separate practitioner performed the reduction. Baseline heart rate, blood pressure, and oxygen saturations were recorded. During the sedation period, the electrocardiogram (ECG) and oxygen saturations were continuously monitored, and non-invasive blood pressure was measured every two minutes in the normal way. An end tidal carbon dioxide monitor was used, which served to demonstrate adequate mask seal and detect apnoea (apnoea was defined as no detectable expired $\mathrm{CO}_{2}$ for more than 20 seconds).

The initial sedative doses were $0.5 \mathrm{mg} / \mathrm{kg}$ of propofol plus $0.5 \mu \mathrm{g} / \mathrm{kg}$ of remifentanil, given intravenously over 60 and 30 seconds, respectively. The first two patients were given $200 \mu \mathrm{g}$ of glycopyrrolate to prevent potential bradycardia, but this appeared to be unnecessary and was subsequently omitted. Shortly after the injections were given, reduction was attempted using the Milch technique. If unsuccessful, additional doses of $0.25 \mathrm{mg} / \mathrm{kg}$ of propofol plus $0.25 \mu \mathrm{g} / \mathrm{kg}$ of remifentanil were given and the procedure repeated.

We recorded the total sedative dose, number of attempts at shoulder reduction, and success rates. After reduction, the patients were asked about recall of events, overall satisfaction, and to assess discomfort on a scale from 0 (no pain) to 10 (worst pain imaginable) with an integer. We noted the times from sedation to reduction, to recovery of alert status, and to discharge.

\section{RESULTS}

We studied nine males and two females. The average age was 28 years (range 17-49). Seven had suffered at least one prior shoulder dislocation. All eleven patients had a successful reduction within four minutes. Seven required one attempt at shoulder reduction, three required two attempts, and one required three attempts.

All patients had adequate sedation and analgesia within three minutes. In eight of the eleven subjects, only one dose of $0.5 \mathrm{mg} / \mathrm{kg}$ propofol and $0.5 \mu \mathrm{g} / \mathrm{kg}$ remifentanil was required. One patient required one additional dose and two patients required two additional doses of $0.25 \mathrm{mg} / \mathrm{kg}$ propofol and $0.25 \mu \mathrm{g} / \mathrm{kg}$ remifentanil. The mean (range) total doses of propofol and remifentanil were 47 (30-80) $\mathrm{mg}$, and 48 (3080) $\mu \mathrm{g}$, respectively.

The mean time to achieve reduction after dosage was 1.6 minutes (range 0.3-4). The mean time to recovery, being clinically alert, was 3.0 minutes (range 1-6). Time spent in

Abbreviations: ASA, American Society of Anesthesiologists; ECG, electrocardiogram; ED, emergency department 
the ED after reduction was an average of 81 minutes (range 30-312). Four patients had their discharge delayed for reasons unrelated to their dislocated shoulder. In the other seven, the mean time to discharge was 49 minutes.

All subjects remained verbally responsive throughout. Recall was reported as full in nine patients, partial in one patient, and one patient had no recall of the reduction. The worst pain scores were a mean of 1.7 (range 0-5). Eight of the eleven patients described the sedation and reduction as "very satisfactory" and the remaining patients described it as "satisfactory".

There were no respiratory or circulatory complications that required treatment. Mean heart rate decreased by 13 beats per minute (16\% decrease from baseline) (range 1-25 bpm, $1-33 \%)$, and mean systolic blood pressure decreased by $18 \mathrm{mmHg}$ ( $12 \%$ decrease from baseline) (range - 12$59 \mathrm{mmHg},-8-34 \%)$. Oxygen saturation decreased in two subjects to $95 \%$ and $94 \%$, but no episodes of apnoea were detected.

\section{DISCUSSION}

Propofol and remifentanil are commonly combined for total intravenous anaesthesia and are being used as conscious sedation for painful procedures. ${ }^{6-9}$ Propofol is rapidly redistributed and a single dose has a short clinical effect. Remifentanil is a potent $\mu$-opioid agonist with an ester linkage that is rapidly broken down by non-specific esterases in tissues and blood. It has an elimination half life of about ten minutes. ${ }^{10}$ Both agents have a rapid onset of action and prompt recovery, ideal for short procedures. They are synergistic both pharmacodynamically ${ }^{11}{ }^{12}$ and pharmacokinetically. ${ }^{13}$ Using both propofol and remifentanil may be better than using either agent alone. ${ }^{68}$ The doses used are approximately a third of those used during anaesthetic procedures.

We found that propofol and remifentanil gave rapid and adequate sedation and analgesia while maintaining patient responsiveness. This allowed shoulder reduction in all patients with a minimal level of discomfort. Traditional agents have lengthy actions so that patients are drowsy for a long time. Rapid recovery is a marked feature of the technique we describe. The subjects became alert quickly and were able to walk unaided in less than 30 minutes. A potential disadvantage of short acting analgesics could be less satisfactory pain relief after the procedure. We did not assess this feature specifically, but no patients needed further analgesics after reduction. In a busy department with limited resources for supervision for long periods, reduced recovery time is a major advantage. The technique was highly acceptable to both patients and staff.

Cardiovascular effects were mild and did not require treatment. Respiratory depression is the most likely complication with this method. There were no recorded apnoeic episodes although two subjects had mild respiratory depression that did not require intervention. The inhibition of ventilation by a $0.5 \mu \mathrm{g} / \mathrm{kg}$ bolus of remifentanil peaks at 2.5 minutes after injection and has ceased after 15 minutes. ${ }^{14}$ Adequate pre-oxygenation using a Mapleson $\mathrm{C}$ circuit gives two important safeguards. First, hypocapnia is prevented so that apnoea is less likely. Second, full pre-oxygenation extends the safety period considerably if transient hypoventilation occurs. This is an important part of our method and we would not consider the procedure without it. Once breathing has re-started, as seen by the bag movements, then a prolonged period of observation is not required.

This evaluation showed that in relatively young fit patients, a combination of propofol and remifentanil provides effective sedation and analgesia while enabling a rapid recovery. A randomised controlled comparison with current methods for reduction of dislocations is now in progress. Specific aspects of the study include assessment of safety in the hands of less experienced administrators and how well the method can be used in older patients.

\section{ACKNOWLEDGEMENTS}

GD had the original idea for the study and co-wrote the paper. RM and CDS performed the study and edited the paper. MD performed the study, co-wrote the paper, and will act as guarantor for the paper.

\section{Authors' affiliations}

M J G Dunn, R Mitchell, Emergency Department, The Royal Infirmary of Edinburgh at Little France, Edinburgh, UK

C D Souza, G Drummond, University Department of Anaesthesia, Critical Care, and Pain Medicine, The Royal Infirmary of Edinburgh at Little France, Edinburgh, UK

Funding: none.

Competing interests: none declared.

Lothian Research Ethics Committee approval was obtained for this study.

The Corresponding Author has the right to grant on behalf of all authors and does grant on behalf of all authors, an exclusive licence (or nonexclusive for government employees) on a worldwide basis to the BMJ Publishing Group Ltd to permit this article (if accepted) to be published in EMJ and any other BMJPGL products and sublicences such use and exploit all subsidiary rights, as set out in our licence (http:// emj.bmijournals.com/misc/ifora/licenceform.shtml).

Correspondence to: Mr M J G Dunn, Emergency Department, The Royal Infirmary of Edinburgh at Little France, 51 Little France Crescent, Old Dalkeith Road, Edinburgh, EH16 4SA, UK; dr@smithsondunn.demon.co. uk

Received 13 October 2004

In revised form 28 January 2005

Accepted for publication 6 February 2005

\section{REFERENCES}

1 Miller SL, Cleeman E, Auerbach J, et al. Comparison of intra-articular lidocaine and intravenous sedation for reduction of shoulder dislocations: a randomized, prospective study. J Bone Joint Surg Am 2002;84-A:2135-9.

2 Kosnik J, Shamsa F, Raphael E, et al. Anesthetic methods for reduction of acute shoulder dislocations: a prospective randomized study comparing intraarticular lidocaine with intravenous analgesia and sedation. Am J Emerg Med 1999; 17:566-70.

3 Orlinsky M, Shon S, Chiang C, et al. Comparative study of intra-articular lidocaine and intravenous meperidine/diazepam for shoulder dislocations. J Emerg Med 2002;22:241-5.

4 Suder PA, Mikkelsen JB, Hougaard K, et al. Reduction of traumatic secondary shoulder dislocations with lidocaine. Arch Orthop Trauma Surg 1995; 114:233-6.

5 Burton JH, Bock AJ, Strout TD, et al. Etomidate and midazolam for reduction of anterior shoulder dislocation: a randomized, controlled trial. Ann Emerg Med 2002;40:496-504.

6 Keidan I, Berkenstadt H, Sidi A, et al. Propofol/remifentanil versus propofol alone for bone marrow aspiration in paediatric haemato-oncological patients. Paediatr Anaesth 2001;11:297-301.

7 Duce D, Glaisyer H, Sury M. An evaluation of propofol combined with remifentanil: a new intravenous anaesthetic technique for short painful procedures in children. Paediatr Anaesth 2000;10:689-90.

8 Holas A, Kraft P, Marcovic M, et al. Remifentanil, propofol or both for conscious sedation during eye surgery under regional anaesthesia. Eur J Anaesthesiol 1999;16:741-8.

9 Reyle-Hahn M, Niggemann B, Max M, et al. Remifentanil and propofol for sedation in children and young adolescents undergoing diagnostic flexible bronchoscopy. Paediatr Anaesth 2000;10:59-63.

10 Glass PS, Hardman D, Kamiyama Y, et al. Preliminary pharmacokinetics and pharmacodynamics of an ultra-short-acting opioid: remifentanil (GI87074B). Anesth Analg 1993;77:1031-40.

11 Ropcke H, Konen-Bergmann M, Cuhls $M$, et al. Propofol and remifentanil pharmacodynamic interaction during orthopedic surgical procedures as measured by effects on bispectral index. J Clin Anesth $2001 ; 13: 198-207$.

12 Conway DH, Hasan SK, Simpson ME. Target-controlled propofol requirements at induction of anaesthesia: effect of remifentanil and midazolam. Eur J Anaesthesiol 2002;19:580-4.

13 Bouillon T, Bruhn J, Radu-Radulescu L, et al. Non-steady state analysis of the pharmacokinetic interaction between propofol and remifentanil. Anesthesiology 2002;97:1350-62.

14 Babenco HD, Conard PF, Gross JB. The pharmacodynamic effect of a remifentanil bolus on ventilatory control. Anesthesiology 2000;92:393-8. 